ORIGINAL ARTICLE

ARTIGO ORIGINAL

\section{Cost-effectiveness of moderate-to-severe psoriasis biologic treatments in Brazilian private healthcare system: cost-per-responder results derived from a network metanalysis}

\author{
Custo-efetividade do tratamento biológico para \\ psoríase moderada a grave no sistema brasileiro de \\ saúde suplementar: resultados de custo por resposta \\ obtidos por meio de uma metanálise em rede \\ André Vicente Esteves de Carvalho', Gleison Vieira Duarte², Mayra lanhez³, \\ Bruno Leonardo Silva ${ }^{4}$, Carla de Agostino Biella ${ }^{4}$, Rafael Freitas dos Santos ${ }^{4}$ \\ DOI: 10.21115/JBES.v12.n3.p231-40
}

\section{Keywords}

psoriasis, biological products, costs and cost analysis,

supplemental health

\begin{abstract}
Objective: To assess the cost-per-responder (CpR) of biologic therapies available in Brazil to treat moderate-to-severe plaque psoriasis $(\mathrm{PsO})$ from the private healthcare system's perspective. Methods: Number needed to treat (NNT) and (CpR) analyses were performed to evaluate biologic therapies' cost-effectiveness for moderate-to-severe PsO available in Brazil. The effectiveness of biologic treatments for moderate-to-severe PsO was assessed based on a previously published metanalysis, which included studies considering PsO patients and outcomes of interest (PASI 75, 90 , and 100). The clinical efficacy data in terms of estimated NNT based on the network metanalysis (NMA) results were combined with drug treatment costs to determine the CpR for each treatment arm in 3-time horizons: the primary response period, 1-year, and 2-years. Results: Risankizumab was the most cost-effective option when NMA base case scenario data was used to calculate NNT in all PASI response for both the primary response period and 1- and 2-years follow-up durations. Differences in $\mathrm{CpR}$ between risankizumab and other biologic drugs increased with more significant PASI improvements. CpR sensitivity analysis also confirmed these findings, indicating that risankizumab has a better performance for PASI 100, and both risankizumab and guselkumab are very similar in terms of cost per additional PASI 75 and PASI 90 responder. Conclusions: Risankizumab was estimated to have a lower cost per PASI 75, 90, and 100 responders in most simulated scenarios (primary response period [12-16 weeks], 1-year and 2-years), among the evaluated biologic therapies.
\end{abstract}

Received on: 11/13/2020. Approved for publication on: 11/19/2020

1. Hospital Moinhos de Vento, Porto Alegre, RS, Brazil.

2. Sociedade Brasileira de Dermatologia, Group for Research and Assessment of Psoriasis and Psoriatic Arthritis, Instituto Bahiano de Imunoterapia, Salvador, BA, Brazil.

3. Universidade Federal de Goiás, Goiânia, GO, Brazil.

4. AbbVie Brazil, São Paulo, SP, Brazil.

Institution where the work was performed: AbbVie Brazil.

Congresses where the study was presented: Not applicable.

Funding: This work was funded by AbbVie. AbbVie participated in the design, work conduct, interpretation of data, review, and publication approval.

Disclosures: André Vicente Esteves de Carvalho has served as an advisory board member and speaker for Abbvie, Jansen, Leo Pharma, Novartis, Lilly, and UCB; Gleison Vieira Duarte is a speaker for Abbvie, Janssen, Lilly, Novartis, Pfizer, Biolab, Leo Pharma, Galderma, Bayer, and Sanofi-Genzyme; Mayra lanhez is a speaker for Abbvie, Janssen, Novartis, UCB, Sanofi-Genzyme, Galderma, Leo Pharma, and Biolab, and served as an advisory board member for Abbvie, Janssen, Novartis, and UCB, and Sanofi-Genzyme; Bruno Leonardo Silva, Carla de Agostino Biella, and Rafael Freitas dos Santos: AbbVie employees and may hold AbbVie stocks and/ or stock options.

Corresponding author: Rafael Freitas dos Santos. Av. Jornalista Roberto Marinho, 85, $7^{\circ}$ andar, Brooklin Novo, São Paulo, SP, Brasil. CEP: 04576-010. Telephone: +55 (11) 94055-3844. E-mail: rafael.freitas@abbvie.com 


\section{Palavras-chave:}

psoríase, produtos biológicos, custos e análise de custo, saúde suplementar

\section{RESUMO}

Objetivo: Avaliar o custo por respondedor (CpR) das terapias biológicas disponíveis no Brasil para tratamento da psoríase em placas ( $\mathrm{PsO}$ ) moderada a grave, na perspectiva do sistema brasileiro de saúde suplementar. Métodos: Foram realizadas análises de número necessário para tratar (NNT) e CpR para avaliar o custo-efetividade das terapias biológicas para PsO moderada a grave disponíveis no Brasil. A eficácia foi avaliada por meio de dados de uma metanálise em rede (NMA), que incluiu estudos considerando pacientes com PsO moderada a grave e os desfechos de interesse (PASI 75, 90 e 100). Dados de eficácia em termos de NNT foram combinados com custos do tratamento medicamentoso para determinar o CpR para cada braço de tratamento em três horizontes temporais: período de resposta primária, 1 ano e 2 anos. Resultados: Risanquizumabe foi mais econômico quando utilizados os dados do caso-base para calcular o NNT, considerando todos os escores PASI para o período de resposta primária e em 1 e 2 anos. As diferenças no CpR entre o risanquizumabe e os outros medicamentos biológicos aumentaram com maiores ganhos de PASI. O CpR calculado pela análise de sensibilidade confirmou esses achados, indicando que risanquizumabe tem um melhor desempenho para PASI 100, e risanquizumabe e guselcumabe são muito semelhantes em termos de CpR por PASI 75 e PASI 90 adicionais. Conclusões: Risanquizumabe apresentou um custo mais baixo por respondedor PASI 75, 90 e 100 na maioria dos cenários analisados (período de resposta primária [12-16 semanas], 1 ano e 2 anos), entre as terapias biológicas avaliadas.

\section{Introduction}

Psoriasis (PsO) is a chronic inflammatory, painful and disabling systemic condition, currently considered of public health concern by the World Health Organization (WHO) (World Health Organization (WHO), 2016). High-quality evidence has observed that PsO patients are at increased risk of several comorbidities such as diabetes mellitus cardiovascular conditions, inflammatory bowel disease, chronic obstructive pulmonary disease, and psychiatric disorders (Ferreira et al., 2016; Fu et al., 2018; Li et al., 2015; Mamizadeh et al., 2019; Richard et al., 2013).

$\mathrm{PsO}$ has a relevant impact on the quality of life (QoL) due to its high disabling potential given by skin involvement and the consequent isolation and/or social discrimination and the eventual joint involvement (Menter et al., 2019). Healthrelated QoL can also be impaired in $\mathrm{PsO}$ patients due to comorbidities associated with the disease, such as metabolic syndrome (Souza et al., 2019).

The most common $\mathrm{PsO}$ type is plaque $\mathrm{PsO}$, usually characterized by well-demarcated red plaques with silvery scales (Menter et al., 2019). In the past 15 years, management of plaque psoriasis has evolved towards biologic medications, targeting various cytokines in $\mathrm{PsO}$ physiopathogenesis such as tumor necrosis factor-alpha (TNF-a), interleukin-12, interleukin-23, and interleukin-17. More recently, other biologic drug classes as the interleukin 23 (IL-23) antagonists have demonstrated a more pronounced reduction in patients' Psoriasis Area and Severity Index (PASI) scores (Gordon et al., 2018).

In this context, studies simultaneously investigating the clinical benefits and incremental costs of PsO therapies are relevant to inform decision-makers about the impact of new drugs on patients' clinical benefits. Health economic evaluations based on cost-per-responder (CpR) have been used to answer this real-world question. They suggest that incremental (CpR) is a valid measure to assess cost-effectiveness in $\mathrm{PsO}$, presenting both clinical and economic significance for care providers and healthcare system managers. Considering the established relationship between PASI response and the impact on patient quality of life, this outcome has been used as an adequate surrogate endpoint to simplify health economic analysis (Armstrong et al., 2018; Ravasio et al., 2019).

Most biologics clinical trials use PASI outcomes as primary endpoints. PASI combines both qualitative and quantitative dimensions of PsO manifestations in a single measure. PASI score varies from 0 (no lesions) to 72 (disease highest degree). Clinical trials usually report the reduction in patient's PASI scores from baseline values after treatment - i.e., a clinical improvement of 75\% (PASI 75), 90\% (PASI 90), or 100\% (PASI 100) (Amatore et al., 2019). Regardless of PASI 75 historically substantial presence as a primary endpoint in $\mathrm{PsO}$ randomized controlled trials (RCT), updates to clinical guidelines have reinforced that PASI 90 response may represent a better efficacy outcome for moderate-to-severe disease. Its achievement is related to higher clinically significant improvements in quality of life, providing patients with greater satisfaction with treatment (Arnone et al., 2019; Puig, 2015). For example, in a posthoc analysis of a phase 2 PsO trial, only 33\% of patients achieving a PASI 75 response reached a DLQI score of 0 or 1 (meaning the lower impact on QoL). In comparison, this proportion was 79\% among PASI 90 responders (EdsonHeredia et al., 2016).

This study aimed to assess the cost-per-responder of biologic therapies available in Brazil to treat moderate-to-severe plaque $\mathrm{PsO}$, under the private healthcare system's perspective, using PASI responses (75, 90, and 100) as efficacy outcomes. 


\section{Methods}

\section{Study design}

The cost-effectiveness of biologic therapies for moderate-to-severe $\mathrm{PsO}$ available in Brazil was evaluated in terms of the number needed to treat (NNT) and cost-per-responder (CpR). The following comparators were included in the analysis (considering marketing authorization in Brazil and available data on the NMA): Adalimumab, Etanercept, Guselkumab, Infliximab, Ixekizumab, Risankizumab, Secukinumab, and Ustekinumab. A responder was defined based on PASI score reduction, with a focus on PASI 90 or higher, as with this response, more than three-quarters of patients have low or no impact on QoL (Edson-Heredia et al., 2016).

\section{Clinical data}

The effectiveness of biologic therapies for PsO was assessed based on a previously published meta-analysis. A Bayesian network meta-analysis, comparing each drug with others having a placebo as a common comparator, was conducted to estimate short-term (10-16 weeks) PASI response rates. The long-term (44-60 weeks) PASI rates were estimated via a traditional meta-analysis (Armstrong et al., 2020). The NMA included short-term randomized controlled trials and longterm trials identified from a systematic literature review (Armstrong et al., 2020). Studies included were phase II and III clinical trials enrolling adults with moderate-to-severe $\mathrm{PsO}$, and that reported the outcomes of interest (PASI 75, 90, and 100). Due to a lack of long term comparative data on the studies, a long-term analysis was performed in two different perspectives: a base case NMA that included Etanercept Ixekizumab, Risankizumab, Secukinumab, and Ustekinumab (comparators with robust long-term evidence), and a pairwise meta-analysis that comprised all phase III studies found in the systematic review as a sensitivity analysis. Thus, five and eight comparators were included in the base case and sensitivity analysis, respectively. In this cost-per-responder $(\mathrm{CpR})$ analysis, most of biologic therapies available in Brazil were included.

Numbers needed to treat (NNT) for additional responder were calculated for each treatment during the primary response period (10-16 weeks) and over one year (44-60 weeks), as the inverse of the absolute risk difference between each active agent and placebo based on the NMA. For two-years analysis, it was assumed the same NNT derived from 1-year period responses, as a conservative approach, considering data was not available in the NMA.

\section{Cost inputs}

The cost per patient in each treatment arm was calculated for short (10-16 weeks) and long-term (up to 2 years) periods. Dosing schedules for some comparators during the primary response period are different from the dosing schedules during the maintenance period. First-year cost and maintenance period costs were considered for cost calculation to get an accurate estimate. The mean weight attributed to patients in the model was $70.0 \mathrm{~kg}$. The proportion of patients with weight $\leq 100 \mathrm{~kg}$ for ustekinumab cost estimation was assumed as 70.0\%, following previous models developed for HTA in Brazil (Edson-Heredia et al., 2016). This study was designed from the Brazilian private health care system's perspective (Sistema de Saúde Suplementar [SSS]). Unit costs included pharmacy costs only and were sourced from the official Brazilian database (Câmara de Regulação do Mercado de Medicamentos [CMED]), considering the ex-factory price added by $18 \%$ of value-added tax (Ministério da Saúde (Brazil), 2019). Monitoring costs (laboratory tests, physician visits, etc.) were not included in the cost estimation once they are not significantly different between biologic drugs considered in the decision model.

\section{Cost per responder calculation}

The clinical efficacy data in terms of estimated NNT based on the NMA results were combined with drug treatment costs to determine each treatment arm's cost-per-responder in 3-time horizons: the primary response period, 1-year, and 2-years. It was computed by multiplying period-specific treatment costs per patient by calculating NNT for the three endpoints of interest (PASI 75, PASI 90, and PASI 100). For the short-term analysis, NNT and their estimated 95\% credible intervals (Crls) as reported by Armstrong et al. (Armstrong et al., 2020) were used to provide a sensitivity range for the CpR, assuming constant unit costs. NNT and their 95\% confidence intervals (Cls) were used for the longterm analysis.

\section{Results}

The NMA in terms of PASI response probabilities and their 95\% Crls (for short-term efficacy) and Cls (for long-term efficacy) are presented in Table 1.

NNT for additional responders were calculated for each treatment during the primary response period (10-16 weeks) and over one year, since the inverse of the absolute risk difference between each active agent and placebo is based on the NMA. For two-year analysis, it was assumed the same NNT derived from 1-year period responses, as a conservative approach, considering data was not available in the NMA. NNT and their 95\% Crl or Cl are shown in Table 2.

\section{Costs}

Details on dosing schedules, unit costs, and cost estimations are presented in Table 3. Mean drug acquisition costs over 1 and 2 years are calculated based on the assumption that all patients remain on treatment during this timeframe with full compliance. 
Table 1. Probability of PASI response for each comparator

\begin{tabular}{|c|c|c|c|c|c|c|c|c|c|}
\hline \multirow{2}{*}{$\begin{array}{l}\text { Treatment } \\
\text { Results from th }\end{array}$} & \multicolumn{3}{|c|}{ Probability of PASI 75} & \multicolumn{3}{|c|}{ Probability of PASI 90} & \multicolumn{3}{|c|}{ Probability of PASI 100} \\
\hline & trials $(1 \mathrm{C}$ & week) - E & mate $\left(95^{\circ}\right.$ & & & & & & \\
\hline Placebo & $5.3 \%$ & $(4.8 \%$ & $5.9 \%)$ & $1.1 \%$ & $(1.0 \%$ & $1.3 \%)$ & $0.1 \%$ & $(0.1 \%$ & $0.1 \%)$ \\
\hline \multirow{2}{*}{$\begin{array}{l}\text { Adalimumab } \\
\text { Etanercept }\end{array}$} & $69.5 \%$ & (66.0\%, & $72.6 \%)$ & $43.7 \%$ & $(40.0 \%$ & $47.4 \%)$ & $16.5 \%$ & $(14.2 \%$ & $19.0 \%)$ \\
\hline & $40.1 \%$ & (35.4\%, & $45.1 \%)$ & $17.9 \%$ & $(14.9 \%$ & $21.4 \%)$ & $4.2 \%$ & $(3.1 \%$ & $5.4 \%)$ \\
\hline Guselkumab & $86.8 \%$ & (83.8\%, & $89.4 \%)$ & $67.3 \%$ & $(62.5 \%$ & $71.9 \%)$ & $35.7 \%$ & (30.9\%, & $40.7 \%)$ \\
\hline Infliximab & $80.4 \%$ & (76.5\%, & $84.0 \%)$ & $57.4 \%$ & (52.2\%, & $62.8 \%)$ & $26.5 \%$ & (22.3\% & $31.4 \%)$ \\
\hline Ixekizumab & $88.8 \%$ & (86.5\%, & $90.9 \%)$ & $70.8 \%$ & (66.8\%, & $74.6 \%)$ & $39.5 \%$ & (35.2\%, & $44.0 \%)$ \\
\hline Risankizumab & $89.2 \%$ & $(86.9 \%$, & $91.3 \%)$ & $71.6 \%$ & $(67.5 \%$ & $75.4 \%)$ & $40.4 \%$ & (35.9\%, & $45.0 \%)$ \\
\hline \multirow{2}{*}{$\begin{array}{l}\text { Secukinumab } \\
\text { Ustekinumab }\end{array}$} & $83.1 \%$ & (80.2\%, & $85.7 \%)$ & $61.4 \%$ & $(57.2 \%$ & $65.6 \%)$ & $29.9 \%$ & $(26.3 \%$ & $33.9 \%)$ \\
\hline & $69.7 \%$ & $(66.3 \%$ & $73.1 \%)$ & $43.9 \%$ & $(40.2 \%$ & $47.9 \%)$ & $16.7 \%$ & $(14.4 \%$ & 19.3\%) \\
\hline \multicolumn{10}{|c|}{ Results from the NMA - long-term trials (44-60 week) - Base Case - Estimate $(95 \% \mathrm{Cl})$} \\
\hline Etanercept & $53.8 \%$ & $(44.1 \%$ & $63.5 \%)$ & $35.9 \%$ & $(27.1 \%$ & $45.6 \%)$ & $15.7 \%$ & $(10.4 \%$ & $22.6 \%)$ \\
\hline Ixekizumab & $83.5 \%$ & (76.2\%. & $89.2 \%)$ & $69.8 \%$ & (60.1\%. & 78.3\%) & $45.0 \%$ & (34.8\%. & $55.6 \%$ \\
\hline Risankizumab & $91.1 \%$ & (87.6\%. & 93.8\%) & $81.3 \%$ & (75.7\%. & $86.1 \%)$ & $59.7 \%$ & (52.1\%. & $67.1 \%)$ \\
\hline \multirow{2}{*}{$\begin{array}{l}\text { Secukinumab } \\
\text { Ustekinumab }\end{array}$} & $80.1 \%$ & (74.7\%. & $84.8 \%)$ & $65.2 \%$ & (58.1\%. & 71.6\%) & $39.9 \%$ & (32.9\%. & $47.3 \%)$ \\
\hline & $69.8 \%$ & (67.3\% & $72.3 \%)$ & $52.5 \%$ & (49.3\%. & $55.7 \%)$ & $28.0 \%$ & (25.2\% & $31.0 \%$ \\
\hline \multicolumn{10}{|c|}{ Results from the NMA - long-term trials (44-60 week) - Sensitivity Analysis - Estimate $(95 \% \mathrm{CI})$} \\
\hline Adalimumab & $71.4 \%$ & $(52.1 \%$ & $85.1 \%)$ & $48.7 \%$ & $(44.1 \%$ & $53.3 \%)$ & $25.6 \%$ & $(20.2 \%$ & $31.9 \%)$ \\
\hline Etanercept & $55.5 \%$ & $(50.1 \%$ & $60.9 \%)$ & $33.4 \%$ & $(28.5 \%$ & $38.7 \%)$ & $10.1 \%$ & $(7.3 \%$ & 13.9\%) \\
\hline Guselkumab & $88.2 \%$ & (84.6\%. & 91.1\%) & $76.5 \%$ & (72.1\%. & $80.5 \%)$ & $47.4 \%$ & (42.5\%. & $52.4 \%)$ \\
\hline Infliximab & $58.3 \%$ & (52.5\%. & $63.8 \%)$ & $40.1 \%$ & (30.0\% & $51.1 \%)$ & - & - & - \\
\hline Ixekizumab & $85.0 \%$ & (79.5\%. & $89.4 \%)$ & $73.9 \%$ & (69.9\%. & $77.5 \%)$ & $54.3 \%$ & (50.0\%. & $58.5 \%)$ \\
\hline Risankizumab & $90.1 \%$ & (86.3\%. & $92.9 \%)$ & $79.4 \%$ & (75.5\%. & $82.9 \%)$ & $56.2 \%$ & (52.4\%. & $59.9 \%)$ \\
\hline Secukinumab & $88.6 \%$ & (80.6\%. & 93.6\%) & $71.3 \%$ & (64.2\%. & $77.5 \%)$ & $42.4 \%$ & (38.5\%. & $46.4 \%)$ \\
\hline Ustekinumab & $72.5 \%$ & (65.9\%. & $78.2 \%)$ & $52.4 \%$ & (47.1\%. & $57.7 \%)$ & $31.0 \%$ & (27.2\% & $35.2 \%)$ \\
\hline
\end{tabular}

PASI: Psoriasis Area and Severity Index; 95\% Crl: 95\% credible interval; NMA: network meta-analysis.

Table 2. NNT for PASI response for each comparator

\begin{tabular}{|c|c|c|c|c|c|c|c|c|c|}
\hline \multirow{2}{*}{$\begin{array}{l}\text { Treatment } \\
\text { Results calculat }\end{array}$} & \multicolumn{3}{|c|}{ NNT for PASI 75} & \multicolumn{3}{|c|}{ NNT for PASI 90} & \multicolumn{3}{|c|}{ NNT for PASI 100} \\
\hline & A-sho & $\mathrm{rm}$ trials & 16 week & timate & Crl) & & & & \\
\hline Adalimumab & 1.56 & $(1.49$ & 1.64) & 2.35 & $(2.16$ & 2.57) & 6.10 & (5.29, & 7.09) \\
\hline Etanercept & 2.87 & $(2.52$ & 3.32) & 5.95 & (4.93, & 7.25) & 24.39 & (18.87, & 32.26) \\
\hline Guselkumab & 1.23 & (1.19, & 1.27) & 1.51 & $(1.41$ & 1.63) & 2.81 & $(2.46$ & $3.25)$ \\
\hline Infliximab & 1.33 & (1.27, & 1.40) & 1.78 & $(1.62$ & 1.96) & 3.79 & (3.21, & $4.50)$ \\
\hline Ixekizumab & 1.20 & $(1.17$ & 1.23) & 1.43 & $(1.36$ & 1.52) & 2.54 & $(2.28$ & 2.85) \\
\hline Risankizumab & 1.19 & (1.16, & 1.23) & 1.42 & $(1.35$ & 1.51) & 2.48 & $(2.23$ & 2.79) \\
\hline \multirow{2}{*}{$\begin{array}{l}\text { Secukinumab } \\
\text { Ustekinumab }\end{array}$} & 1.29 & $(1.24$ & 1.34) & 1.66 & $(1.55$ & 1.78) & 3.36 & $(2.96$ & 3.82) \\
\hline & 1.55 & $(1.48$, & 1.64) & 2.34 & $(2.14$ & 2.56) & 6.02 & $(5.21$ & 6.99) \\
\hline \multicolumn{10}{|c|}{ Results calculated based on the NMA - long-term trials (44-60 week) - Base Case - Estimate $(95 \% \mathrm{Cl})$} \\
\hline Etanercept & 1.86 & $(1.57$ & 2.27) & 2.79 & $(2.19$ & 3.69) & 6.37 & $(4.42$ & 9.62) \\
\hline Ixekizumab & 1.20 & (1.12, & 1.31) & 1.43 & $(1.28$ & 1.66) & 2.22 & (1.80, & 2.87) \\
\hline Risankizumab & 1.10 & (1.07, & 1.14) & 1.23 & (1.16, & 1.32) & 1.68 & $(1.49$ & 1.92) \\
\hline \multirow{2}{*}{$\begin{array}{l}\text { Secukinumab } \\
\text { Ustekinumab }\end{array}$} & 1.25 & (1.18, & 1.34) & 1.53 & $(1.40$ & 1.72) & 2.51 & $(2.11$ & 3.04) \\
\hline & 1.43 & (1.38, & 1.49) & 1.90 & $(1.80$ & 2.03) & 3.57 & (3.23, & 3.97) \\
\hline \multicolumn{10}{|c|}{ Results calculated based on the NMA - long-term trials ( $44-60$ week) - Sensitivity Analysis - Estimate ( $95 \% \mathrm{CI})$} \\
\hline Adalimumab & 1.40 & $(1.18$ & 1.92) & 2.05 & $(1.88$ & 2.27) & 3.91 & $(3.13$ & 4.95) \\
\hline Etanercept & 1.80 & $(1.64$, & 2.00) & 2.99 & $(2.58$, & 3.51) & 9.90 & $(7.19$ & 13.70) \\
\hline Guselkumab & 1.13 & (1.10, & 1.18) & 1.31 & $(1.24$ & 1.39) & 2.11 & (1.91, & 2.35) \\
\hline Infliximab & 1.72 & (1.57, & 1.91) & 2.49 & $(1.96$ & 3.33) & - & - & - \\
\hline Ixekizumab & 1.18 & $(1.12$ & 1.26) & 1.35 & $(1.29$ & 1.43) & 1.84 & $(1.71$ & 2.00) \\
\hline Risankizumab & 1.11 & $(1.08$, & 1.16) & 1.26 & $(1.21$ & 1.32) & 1.78 & $(1.67$, & 1.91) \\
\hline Secukinumab & 1.13 & (1.07, & 1.24) & 1.40 & $(1.29$ & 1.56) & 2.36 & $(2.16$ & 2.60) \\
\hline Ustekinumab & 1.38 & $(1.28$, & 1.52) & 1.91 & $(1.73$ & 2.12) & 3.23 & $(2.84$ & 3.68) \\
\hline
\end{tabular}

NNT: number needed to treat; $95 \%$ Crl: 95\% credible interval; NNT for each active drug were calculated versus placebo, respectively. 
Table 3. Cost input data and cost estimate per treatment period for each comparator

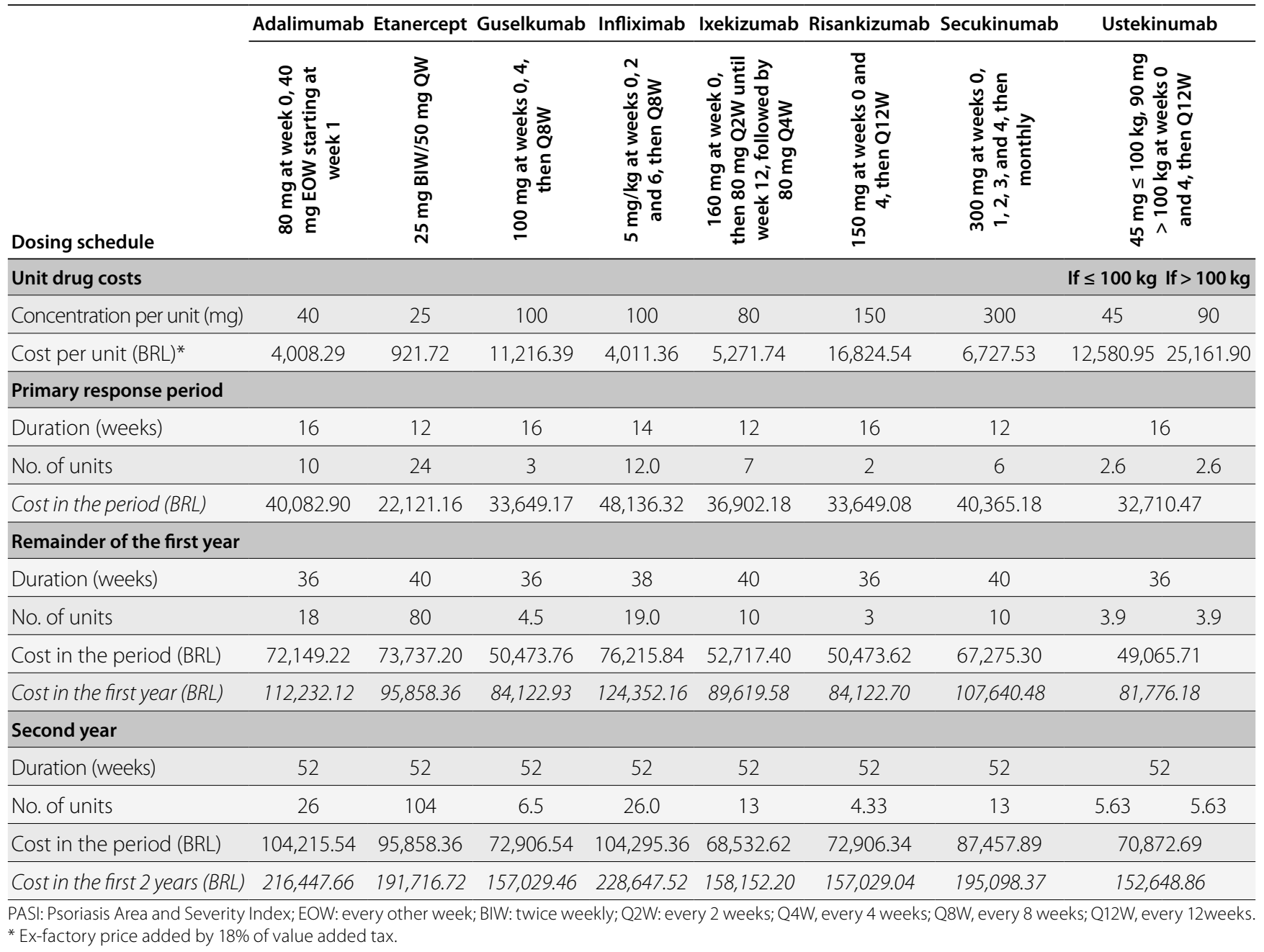

\section{Cost per responder in the NMA base-case scenario}

Table 4 presents the $\mathrm{CpR}$ analysis results per each PASI response and comparator for the three-time horizons, considering NMA base-case results. In all time frames and PASI response criteria (75, 90, and 100), the lower CpR observed was for risankizumab and guselkumab. In the primary response period, the second lower CpR was ixekizumab for PASI 100. For 1- and 2-year time horizons, the second CpR was observed for ixekizumab. The highest CpR was observed for etanercept in PASI 90 and PASI 100 responses in the primary response period. The most increased $\mathrm{CpR}$ in the long-term analysis (1-and 2-years) was seen in all PASI response criteria. The highest $C p R$ in the short-term was observed for infliximab in PASI 75 response (Figure 1).

\section{Cost per responder in NMA sensitivity analysis}

Estimated response rates from the NMA of short-term PASI sensitivity analyses included global trials and phase III trials only and expanded treatment space. Considering the NMA sensitivity analysis (Armstrong et al., 2020), which included all eight medications in 1- and 2-year time horizons, the lowest
CpR for PASI 75 and PASI 90 was achieved by risankizumab and guselkumab. Risankizumab showed the lowest CpR for PASI 100. The highest CpRs are observed for infliximab for PASI 75 and etanercept for PASI 90 and PASI 100. A similar pattern was observed in 2 years of treatment (Table 5, Figure 2).

Figure 3 shows the sensitivity analysis results using the lower and upper limits of the respective $95 \% \mathrm{Crl}$ to provide a range interval for cost per PASI 75, 90, and 100 responders in the primary response period. In all comparisons, risankizumab had a lower mean CpR. The same pattern was observed in 1- and 2-years PASI 100 response. For other PASI thresholds in 2-years, risankizumab and guselkumab had very similar cost-per-responder 95\% Crl ranges for both PASI 75 (BRL 169,030 to 181,957 and BRL 172,432 to 185,532 , respectively) and PASI 90 (BRL 189,420 to 207,985 and BRL 195,163 to 217,872, respectively).

\section{Discussion}

The current cost-per-responder analysis adopted a methodologically rigorous network meta-analysis of biologic medications for moderate-to-severe PsO to identify the effectiveness of each therapeutic option (Armstrong et al., 2020). 
Table 4. Cost per responder according to PASI response and treatment duration - NMA base case results

\begin{tabular}{|c|c|c|c|c|}
\hline Treatment & Drug costs* & $\mathrm{iCpR}-\mathrm{PASI} 75^{* *}$ & iCpR - PASI90** & iCpR - PASI $100^{* *}$ \\
\hline \multicolumn{5}{|c|}{ Primary response period - Estimate $(95 \% \mathrm{Crl})$} \\
\hline Adalimumab & 40,083 & $62,434(59,559-65,926)$ & $94,091(86,572-103,041)$ & $244,408(212,079-284,276)$ \\
\hline Etanercept & 22,121 & $63,567(55,721-73,492)$ & $131,674(108,971-160,298)$ & $539,540(417,380-713,586)$ \\
\hline Guselkumab & 33,649 & $41,338(40,011-42,865)$ & $50,906(47,594-54,803)$ & $94,520(82,880-109,251)$ \\
\hline Infliximab & 48,136 & $64,096(61,164-67,607)$ & $85,500(78,017-94,200)$ & $182,335(154,283-216,830)$ \\
\hline Ixekizumab & 36,902 & $44,194(43,160-45,502)$ & $52,944(50,207-56,168)$ & $93,660(84,060-105,134)$ \\
\hline Risankizumab & 33,649 & $40,106(39,127-41,237)$ & $47,729(45,288-50,676)$ & $83,496(74,942-93,992)$ \\
\hline Secukinumab & 40,365 & $51,950(50,205-53,892)$ & $67,052(62,679-71,952)$ & $135,454(119,424-154,066)$ \\
\hline Ustekinumab & 32,710 & $50,793(48,676-53,188)$ & $76,426(70,194-83,445)$ & $197,051(170,367-228,745)$ \\
\hline \multicolumn{5}{|c|}{1 year of treatment - Estimate $(95 \% \mathrm{Cl})$} \\
\hline Etanercept & 95,858 & $178,175(150,958-217,366)$ & $267,015(210,216-353,721)$ & $610,563(424,152-921,715)$ \\
\hline Ixekizumab & 89,620 & $107,329(100,470-117,611)$ & $128,395(114,457-149,117)$ & $199,155(161,186-257,528)$ \\
\hline Risankizumab & 84,123 & $92,341(89,683-96,030)$ & $103,472(97,703-111,126)$ & $140,909(125,369-161,464)$ \\
\hline Secukinumab & 107,640 & $134,383(126,935-144,097)$ & $165,093(150,336-185,268)$ & $269,776(227,570-327,175)$ \\
\hline Ustekinumab & 81,776 & $117,158(113,107-121,510)$ & $155,764(146,815-165,875)$ & $292,058(263,794-324,509)$ \\
\hline \multicolumn{5}{|c|}{2 years of treatment - Estimate $(95 \% \mathrm{Cl})$} \\
\hline Etanercept & 191,717 & $356,351(301,916-434,732)$ & $534,030(420,431-707,442)$ & $1,221,126(848,304-1,843,430)$ \\
\hline Ixekizumab & 158,152 & $189,404(177,301-207,549)$ & $226,579(201,982-263,148)$ & $351,449(284,446-454,460)$ \\
\hline Risankizumab & 157,029 & $172,370(167,408-179,257)$ & $193,148(182,380-207,436)$ & $263,030(234,022-301,399)$ \\
\hline Secukinumab & 195,098 & $243,569(230,069-261,176)$ & $299,231(272,484-335,798)$ & $488,968(412,470-593,004)$ \\
\hline Ustekinumab & 152,649 & $218,695(211,133-226,819)$ & $290,760(274,055-309,633)$ & $545,175(492,416-605,749)$ \\
\hline
\end{tabular}

iCpR: incremental cost-per-responder; PASI: Psoriasis Area and Severity Index; Crl: credible interval.

* Drug acquisition costs within the period expressed in BRL (Brazilian real [currency]); Brazilian official database (Câmara de Regulação do Mercado de Medicamentos [CMED]), considering the ex-factory price added by $18 \%$ of value added tax. ${ }^{* *}$ BRL.

Table 5. Cost per responder according to PASI response and treatment duration using NMA sensitivity analysis results

\begin{tabular}{|c|c|c|c|c|}
\hline Treatment & $\begin{array}{l}\text { Drug acquisition cost } \\
\text { within the period (BRL) }\end{array}$ & $\begin{array}{l}\text { iCpR - PASI75 } \\
\text { (BRL) }\end{array}$ & $\begin{array}{l}\text { iCpR - PASI90 } \\
\text { (BRL) }\end{array}$ & $\begin{array}{l}\mathrm{iCpR}-\mathrm{PASI} 100 \\
\text { (BRL) }\end{array}$ \\
\hline \multicolumn{5}{|c|}{ First year of treatment } \\
\hline Adalimumab & 112,232 & 157,188 & 230,456 & 438,407 \\
\hline Etanercept & 95,858 & 172,718 & 287,001 & 949,093 \\
\hline Guselkumab & 84,123 & 95,347 & 109,927 & 177,291 \\
\hline Infliximab & 124,352 & 213,418 & 309,898 & - \\
\hline Ixekizumab & 89,620 & 105,435 & 121,271 & 165,045 \\
\hline Risankizumab & 84,123 & 93,366 & 105,948 & 149,685 \\
\hline Secukinumab & 107,640 & 121,490 & 150,968 & 253,869 \\
\hline Ustekinumab & 81,776 & 112,795 & 156,061 & 263,794 \\
\hline \multicolumn{5}{|c|}{2 years of treatment } \\
\hline Adalimumab & 216,448 & 303,148 & 444,451 & 845,499 \\
\hline Etanercept & 191,717 & 345,436 & 574,002 & $1,898,185$ \\
\hline Guselkumab & 157,029 & 177,982 & 205,197 & 330,944 \\
\hline Infliximab & 228,648 & 392,414 & 569,812 & - \\
\hline Ixekizumab & 158,152 & 186,061 & 214,008 & 291,256 \\
\hline Risankizumab & 157,029 & 174,283 & 197,770 & 279,411 \\
\hline Secukinumab & 195,098 & 220,201 & 273,630 & 460,138 \\
\hline Ustekinumab & 152,649 & 210,550 & 291,315 & 492,416 \\
\hline
\end{tabular}

iCpR: incremental cost-per-responder; PASI: Psoriasis Area and Severity Index. 

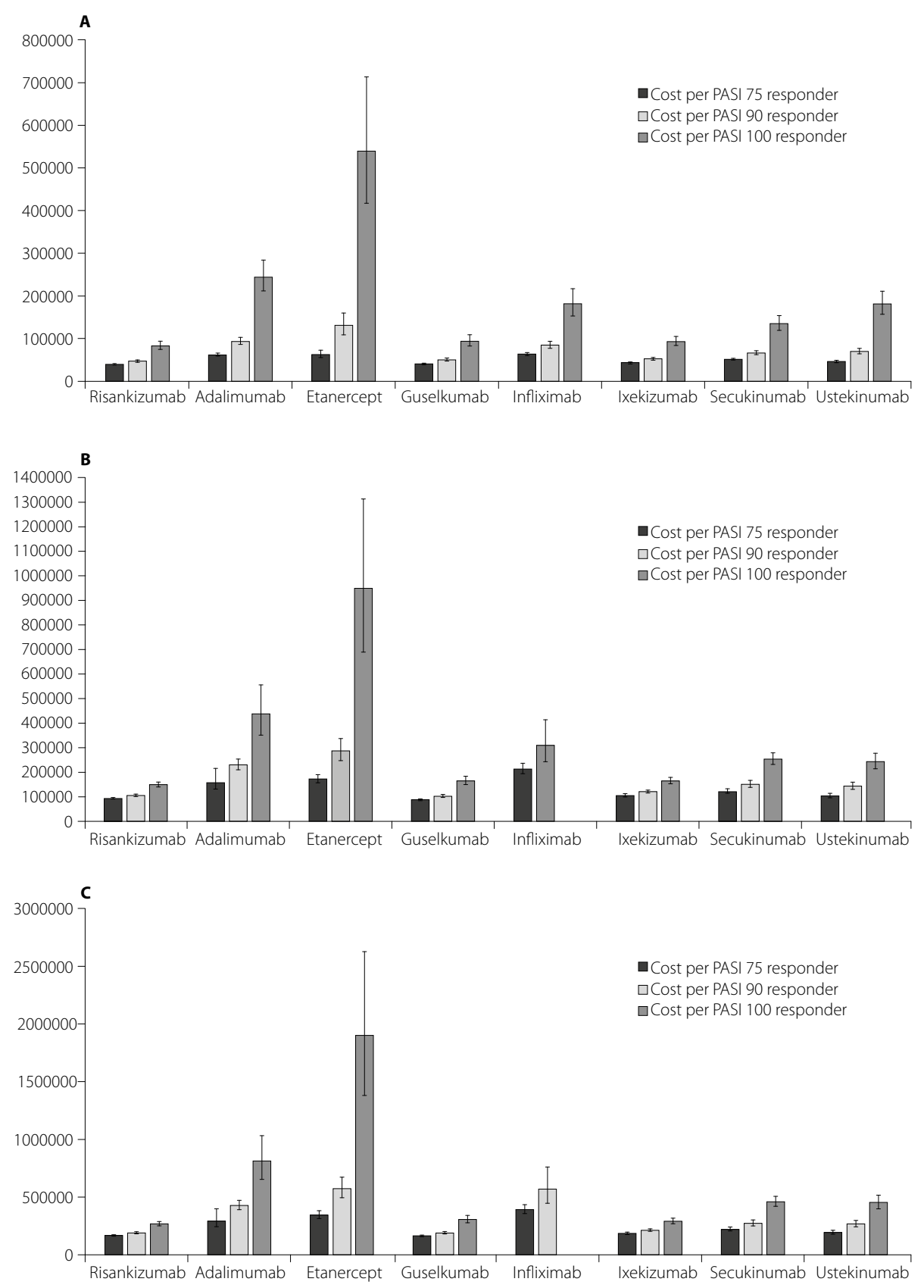

95\% Cl: 95\% confidence interval; NMA: network metanalysis; PASI: psoriasis area severity index.

Figure 1. Cost per responder and $95 \% \mathrm{Cl}$ for each biologic considering NMA base case results: A) primary response period; B) first year of treatment; C) 2 years of treatment.

The analysis allowed a simultaneous comparison of 5 to 8 biologic drugs (depending on the time horizon and scenario) and three different PASI outcomes, providing a comprehensive overview of clinical benefits and costs associated with $\mathrm{PsO}$ biologic therapy. Given the introduction of novel biologic treatments in the therapeutic armamentarium for moderate-to-severe $\mathrm{PsO}$ in Brazil, this long-term analysis can help guide resource allocation decision-making.
Risankizumab was the most cost-effective option when NMA base case scenario data was used to calculate NNT, using all PASI thresholds for both the primary response period and 1- and 2-year follow-up durations. Overall, differences in the cost-per-responder between risankizumab and the other biologic drugs increased with more significant PASI improvements. The cost-per-responder sensitivity analysis also confirmed these findings, indicating that risankizumab has a better performance 

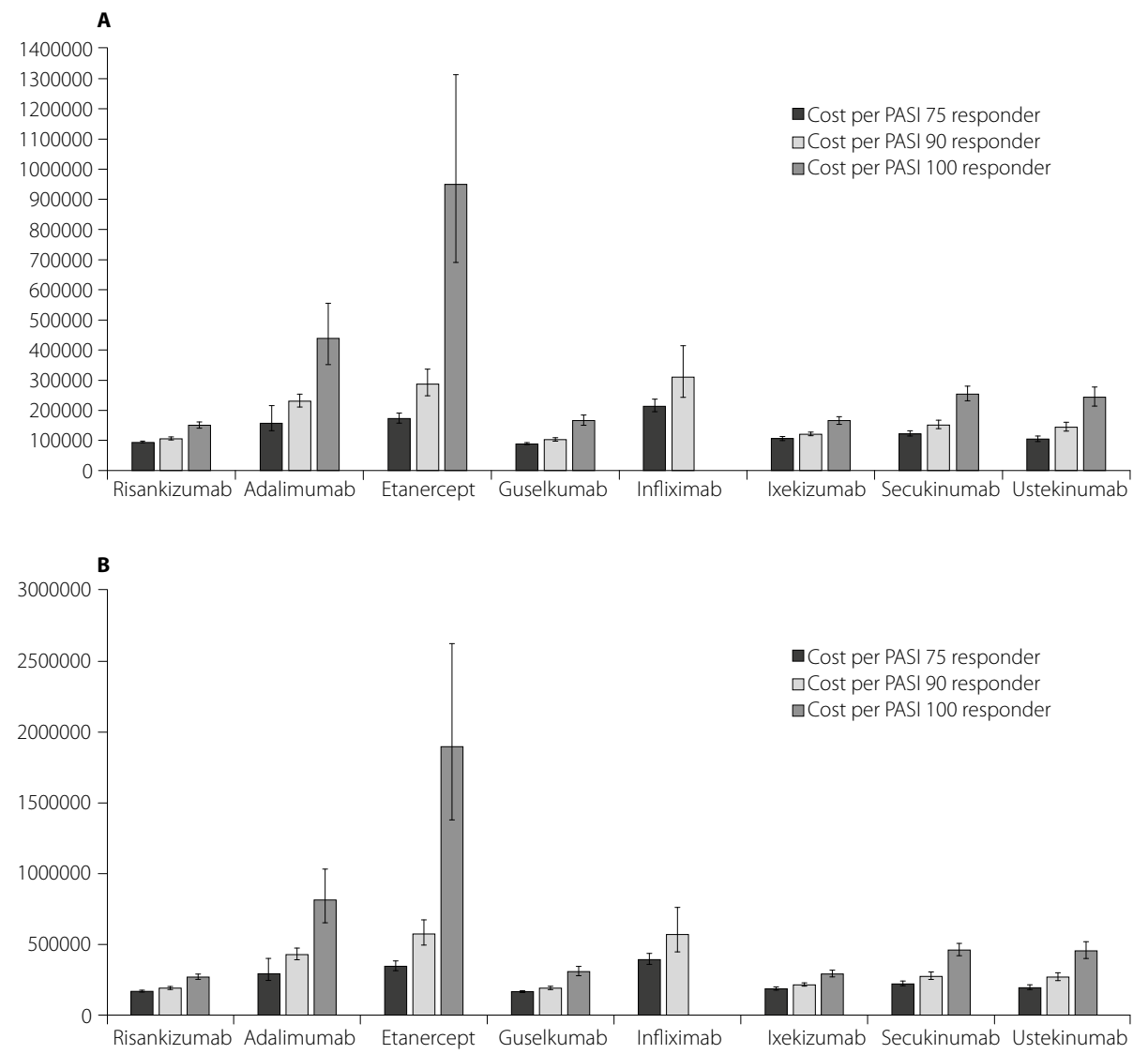

95\% Cl: 95\% confidence interval; PASI: psoriasis area severity index.

Figure 2. Cost per responder and 95\% Cl for each biologic considering the sensitivity analysis: A) first year of treatment; B) 2 years of treatment.

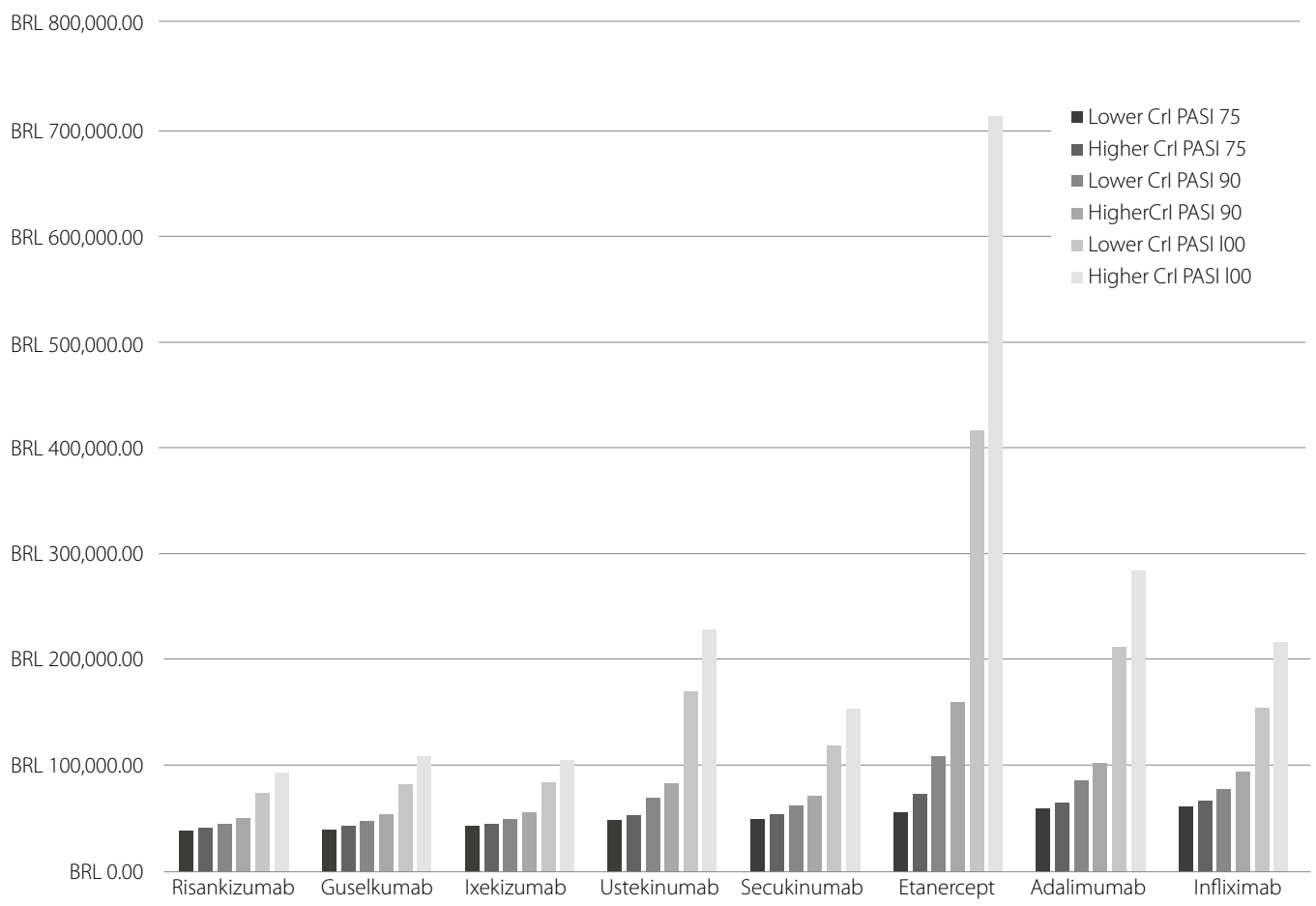

95\% Crl: 95\% credible intervals; BRL: Brazilian real [currency]; NMA: network metanalysis; PASI: psoriasis area severity index

Figure 3. Cost per responder results using lower and upper limits of 95\% Crl reported in the NMA. 
for PASI 100 and risankizumab and guselkumab are very similar in cost per additional PASI 75 and PASI 90 responder.

Estimated response results in the $\mathrm{CpR}$ analysis are consistent with findings from a recent Cochrane network meta-analysis simultaneously comparing several drug classes and unique drugs for moderate-to-severe $\mathrm{PsO}$ in follow-up durations ranging from 8-24 weeks (Sbidian et al., 2017). To achieve a short-term PASI 90 response, the authors identified that the anti-IL23 drugs risankizumab and guselkumab were significantly more effective than ustekinumab, adalimum$\mathrm{ab}$, certolizumab and etanercept, as well as were infliximab and all of the anti-IL17 drugs. The efficacy point estimates for these drugs were compatible. Similar conclusions were reached by other authors (Sawyer et al., 2019).

Key strengths of this cost-per-responder analysis include the longer time horizon, the robustness of the NMA providing clinical data, and the inclusion of all biologic drug classes available to $\mathrm{PsO}$ patients in Brazil. However, the analysis is subject to some limitations. For instance, CpR did not consider safety and tolerability issues as other cost-effectiveness analyses. This factor may have underestimated all comparators' treatment costs, particularly for those presenting a less favorable safety profile. Additionally, real-world data about costs and efficacy in Brazil were not available, impairing our ability to have a more in-depth understanding of drug effectiveness outside clinical trials and more comprehensive estimate of treatment costs. Infliximab CpR potential underestimation due to weight estimate may be considered a limitation of the present analysis. Furthermore, biosimilars and certolizumab pegol (licensed in Brazil for PsO) were not included in the $\mathrm{CpR}$ analysis. Further research is warranted to assess the economic burden of adverse events and to estimate real-world data to improve the external validity of PsO biologic drugs economic evaluations.

\section{Conclusion}

Among the evaluated biologic therapies, risankizumab was estimated to have a lower cost per PASI 75, 90, and 100 responders in most simulated scenarios (primary response period [12-16 weeks], 1-year and 2-years). Its clinical and economic benefits were remarkably consistent in PASI 100 threshold. As some of these drugs had recent approval in the country, the analysis provided relevant and innovative data about the clinical and economic impact of new therapeutic options for Brazilian PsO patients, care providers, and the healthcare system.

\section{Acknowledgements}

We would like to recognize the assistance of ANOVA Health Consulting Group and Maíra Takemoto from ANOVA that provided medical writing assistance in this manuscript, funded by AbbVie.
We would like to acknowledge Leilane P. Danze, of AbbVie, for her internal publication process and medical writing assistance.

\section{References}

Amatore F, Villani AP, Tauber M, Viguier M, Guillot B. French guidelines on the use of systemic treatments for moderate-to-severe psoriasis in adults. J Eur Acad Dermatol Venereol. 2019;33(3):464-83.

Armstrong AW, Betts KA, Signorovitch JE, Sundaram M, Li J, Ganguli AX, et al. Number needed to treat and costs per responder among biologic treatments for moderate-to-severe psoriasis: a network meta-analysis. Curr Med Res Opin. 2018;34(7):1325-33.

Armstrong AW, Puig L, Joshi A, Skup M, Williams D, Li J, et al. Comparison of Biologics and Oral Treatments for Plaque Psoriasis: A Meta-analysis. JAMA Dermatol. 2020;156(3):258-69.

Arnone M, Takahashi MDF, de Carvalho AVE, Bernardo WM, Bressan AL, Ramos AMC, et al. Diagnostic and therapeutic guidelines for plaque psoriasis - Brazilian Society of Dermatology. An Bras Dermatol. 2019;94(2):76-107.

Edson-Heredia E, Banerjee S, Zhu B, Maeda-Chubachi T, Cameron GS, Shen $W$, et al. A high level of clinical response is associated with improved patient-reported outcomes in psoriasis: Analyses from a phase 2 study in patients treated with ixekizumab. J Eur Acad Dermatol Venereol. 2016:30(5):864-5.

Ferreira BI, Abreu JL, Reis JP, Figueiredo AM. Psoriasis and associated psychiatric disorders: A systematic review on etiopathogenesis and clinical correlation. J Clin Aesthet Dermatol. 2016;9(6):36-43.

Fu Y, Lee CH, Chi CC. Association of Psoriasis with Inflammatory Bowel Disease: A Systematic Review and Meta-analysis. JAMA Dermatol. 2018;154(12):1417-23.

Gordon KB, Strober B, Lebwohl M, Augustin M, Blauvelt A, Poulin Y, et al. Efficacy and safety of risankizumab in moderate-to-severe plaque psoriasis (UItIMMa-1 and UItIMMa-2): results from two double-blind, randomised, placebo-controlled and ustekinumab-controlled phase 3 trials. Lancet. 2018;392(10148):650-61.

Li X, Kong L, Li F, Chen C, Xu R, Wang H, et al. Association between psoriasis and chronic obstructive pulmonary disease: A systematic review and meta-analysis. PLoS One. 2015;10(12):e0145221.

Mamizadeh M, Tardeh Z, Azami M. The association between psoriasis and diabetes mellitus: A systematic review and meta-analysis. Diabetes Metab Syndr. 2019;13(2):1405-12.

Menter A, Strober BE, Kaplan DH, Kivelevitch D, Prater EF, Stoff B, et al. Joint AAD-NPF guidelines of care for the management and treatment of psoriasis with biologics. J Am Acad Dermatol. 2019;80(4):1029-72.

Ministério da Saúde (Brasil). Câmara de Regulação do Mercado de Medicamentos (CMED) [Internet]. 2019. Available from: https://www.gov. br/anvisa/pt-br/assuntos/medicamentos/cmed

Puig L. PASI90 response: the new standard in therapeutic efficacy for psoriasis. J Eur Acad Dermatol Venereol. 2015;29(4):645-8.

Ravasio R, Antonelli S, Maiorino A, Costanzo A, Losi S. Cost per responder for ixekizumab and other biologic drugs approved for the treatment of moderate-to-severe plaque psoriasis in Italy. Glob Reg Heal Technol Assess. 2019.

Richard MA, Barnetche T, Horreau C, Brenaut E, Pouplard C, Aractingi S, et al. Psoriasis, cardiovascular events, cancer risk and alcohol use: Evidencebased recommendations based on systematic review and expert opinion. J Eur Acad Dermatol Venereol. 2013;27(Suppl 3):2-11. 
Sawyer LM, Malottki K, Sabry-Grant C, Yasmeen N, Wright E, Sohrt A, et al. Assessing the relative efficacy of interleukin-17 and interleukin-23 targeted treatments for moderate-to-severe plaque psoriasis: A systematic review and network meta-analysis of PASI response. PLoS One. 2019;14(8):e0220868.

Sbidian E, Chaimani A, Garcia-Doval I, Do G, Hua C, Mazaud C, et al. Systemic pharmacological treatments for chronic plaque psoriasis: A network meta-analysis. Cochrane Database Syst Rev. 2017;12(12):CD011535.
Souza CS, de Castro CCS, Carneiro FRO, Pinto JMN, Fabricio LHZ, AzulayAbulafia L, et al. Metabolic syndrome and psoriatic arthritis among patients with psoriasis vulgaris: Quality of life and prevalence. J Dermatol. 2019;46(1):3-10.

World Health Organization (WHO). Global Report on Psoriasis. Geneva: WHO Press; 2016. 48p. 